\title{
Navigating troubled waters: Hyperglycaemic Hyperosmolar State precipitated by Nephrogenic Diabetes Insipidus
}

\author{
P Avari', A Sharma'1, S Samarasinghe', Q Barnor ${ }^{1}$ \\ ${ }^{1}$ Department of Endocrinology, Watford General Hospital, West Hertfordshire Hospitals NHS Trust
}

\section{INTRODUCTION}

O Hyperglycaemic hyperosmolar state (HHS) is a common medical presentation, typically occurring in older patients with Type 2 diabetes mellitus.

O Mortality rates of up to $60 \%$ have been reported.

- We describe a rare case of HHS, likely to be precipitated post lithium-induced nephrogenic diabetes insipidus (DI).

\section{CASE HISTORY}

- A 62-year-old female with bipolar disorder presented to ED with lethargy, confusion and reduced mobility.

- Past medical history: bipolar disorder, hypothyroidism and recurrent UTIs.

- Medication history: lithium (>10 years duration), diazepam, olanzapine, sodium valproate and levothyroxine.

- She remained persistently hypernatraemic with $\mathrm{Na}$ $>170 \mathrm{mmol} / \mathrm{L}$ despite commencement of intravenous fluids.

- 10 days after admission, her blood glucose was noted to be $35 \mathrm{mmol} / \mathrm{L}$ with serum osmolality of $398 \mathrm{mOsm} / \mathrm{kg}$

- She was deemed to be in $\underline{\mathbf{H H S}}$ and treatment commenced with fixed rate insulin infusion and $0.9 \%$ saline.

- Over the next few days, the patient's clinical state deteriorated and she was transferred to ITU.

- Despite a fall in blood glucose, her plasma Na remained persistently elevated despite intravenous $0.45 \%$ saline.

- She remained polyuric with an increasing plasma osmolality and a low urine osmolality. This prompted the consideration of nephrogenic DI as a concomitant pathology.

- Overnight water deprivation test confirmed the diagnosis of DI

\section{INITIAL INVESTIGATIONS}

\section{Bloods:}

$\mathrm{Hb} 109 \mathrm{~g} / \mathrm{dL}$, WCC $12 \times 10^{9} / \mathrm{I}$, Neu $9.0 \times 10^{9} / \mathrm{I}$

$\mathrm{Na} 143 \mathrm{mmol} / \mathrm{L}, \mathrm{K} 4.0 \mathrm{mmol} / \mathrm{L}$, Urea $7 \mathrm{mmol} / \mathrm{L}, \mathrm{Cr} 98 \mathrm{mmol} / \mathrm{L}$

TFTs- normal

Lithium levels $1 \mathrm{mmol} / \mathrm{L}(0.4-0.8 \mathrm{mmol} / \mathrm{L})$

$\mathrm{HbA} 1 \mathrm{c}$ (IFCC): $36 \mathrm{mmol} / \mathrm{mol}$ (5.4\% six months pre-

admission)

\section{Venous blood gas: $\mathrm{pH} 7.43$, bicarbonate $25.9 \mathrm{mmol} / \mathrm{L}$}

ECG: normal sinus rhythm

CXR/Urine dip: negative

\section{RESULTS}

\begin{tabular}{|c|c|c|c|}
\hline & Pre-HHS treatment & Post-HHS treatment & Post-DI treatment \\
\hline Glucose (mmol/L) & 35 & 7 & - \\
\hline $\begin{array}{c}\text { Serum Osmolality } \\
\text { (mOsmol/kg) }\end{array}$ & 398 & 350 & 289 \\
\hline $\begin{array}{c}\text { Urine Osmolality } \\
\text { (mOsmol/kg) }\end{array}$ & - & 219 & 267 \\
\hline Serum Na (mmol/L) & 176 & 150 & 144 \\
\hline
\end{tabular}

\section{MANAGEMENT}

- $\quad$ Amiloride with hydrochlorothiazide was started as treatment for nephrogenic DI.

- Subsequent improvement was observed with falling serum osmolalities and plasma sodium.

- Her plasma glucose remained stable on oral antihyperglycaemic agents.

\section{Discussion \& Learning Points}

- Nephrotoxic renal effects of lithium may occur even within what is considered a therapeutic range.

- Lithium acts through entering the collecting ducts through epithelial sodium channels (ENaC) and inhibits signalling pathways (adenylate cyclase and glycogen synthase3-beta) causing disruption of the aquaporin-2 structure. These changes are initially reversible but thereafter can become permanent.

- Following recovery of hyperglycaemia, persistent polyuria and hyperosmolar state should prompt consideration of differentials to include diabetes insipidus.

- Amiloride and hydrochlorthiazide are effective in the treatment of nephrogenic diabetes insipidus.

- It is important to recognise the two conditions may coexist in the same patient, so that appropriate therapies may be initiated.

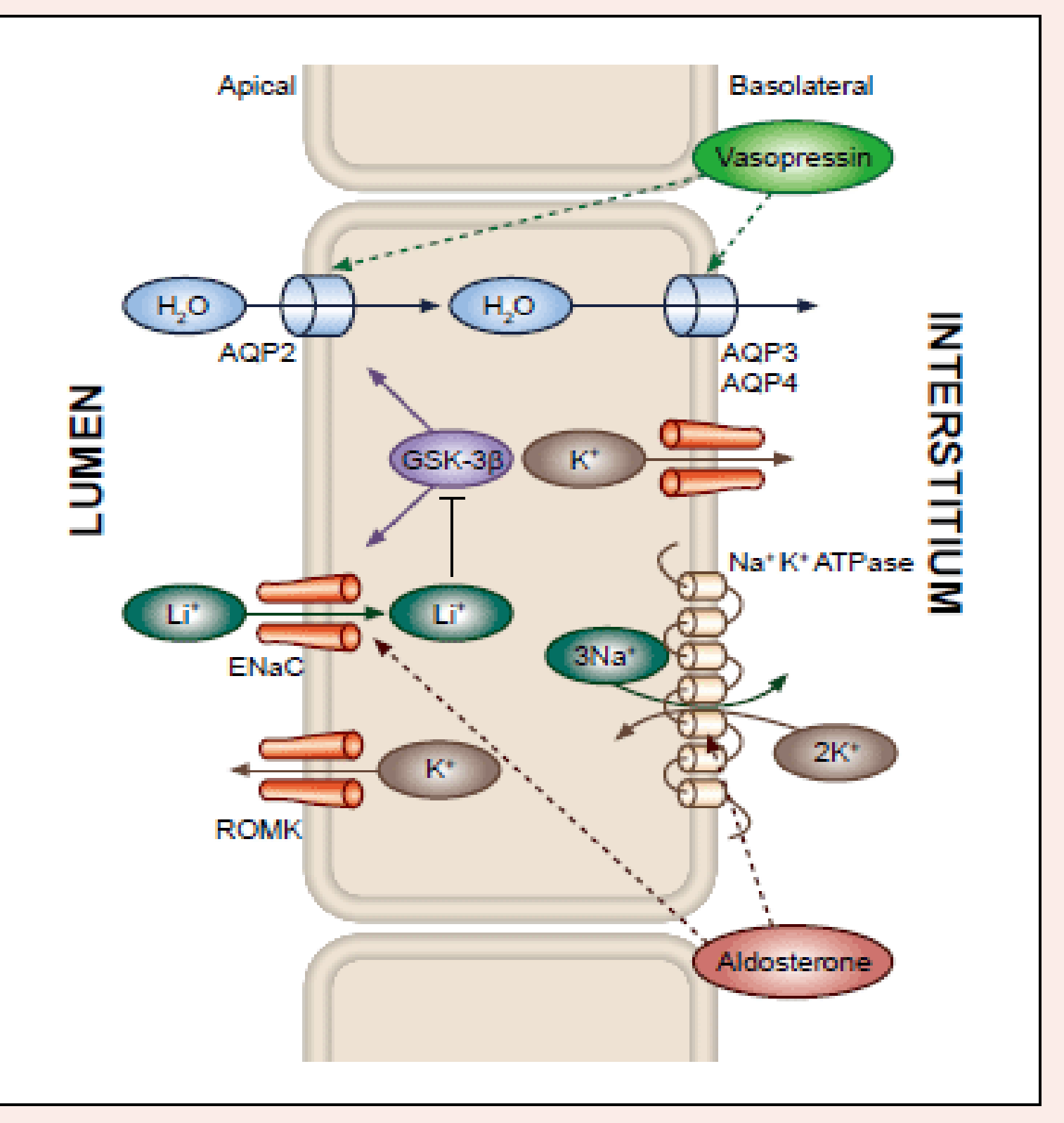

